InterAção | 83

\title{
POR UMA LEITURA MAIS AMPLA: A CONTRIBUIÇÃO DA HISTORIOGRAFIA NAS RELAÇÕES INTERNACIONAIS
}

\author{
Alan Gabriel Camargo ${ }^{1}$
}

\section{Resumo}

O objetivo central deste artigo é entender, a partir da análise das tradições francesa e inglesa, as contribuições conferidas pela Historiografia ao estudo das Relações Internacionais. Para isso, traçar-se-á inicialmente a perspectiva sobre o domínio do campo historiográfico e, concomitantemente, resgatar-se-á as primeiras literaturas historicistas voltadas à compreensão dos acontecimentos internacionais. Em seguida, os contornos que marcam as tradições historiográficas francesa e inglesa serão elucidados, respectivamente, a partir de DUROSELLE (2000) e BULL (2002), seus representantes por excelência. Por meio de um balanço que analise o alcance e as falhas de cada uma das tradições mencionadas, o trabalho se aterá aos efeitos que as dinâmicas globais geram a tais produções intelectuais. A partir dessas considerações, o artigo concluíra as discussões apresentadas ao compreender os meios historiográficos como formas de estudar mais amplificada, tanto contextual quanto cognitivamente, as Relações Internacionais.

1 Mestrando em Relações Internacionais. Instituto de Relações Internacionais - Universidade de Brasília. E-mail: camargo_bariri@yahoo.com.br 
84 | InterAção

Palavras-chave: Historiografia. Relações Internacionais.Tradição Francesa. Tradição Inglesa.

Abstract

The central objective of this paper is to understand the contribution of Historiography to the study of International Relations from the analysis of the French and English traditions. For this purpose, it will draw firstly the perspective on the historiographical field and concomitantly it will rescue the first historicist literature aimed at the understanding of international events. Then, the contours that mark the French and English historiographical traditions will be elucidated, respectively, with DUROSELLE (2000) and BULL (2002), their representatives par excellence. Through a balance to examine the scope and failures of each mentioned traditions, the article will focus the effects that the global dynamics grant to such intellectual productions. From these considerations, the paper will conclude the discussions understanding the historiographical studies as means to read the International Relations more amplified contextual and cognitively.

Keywords: Historiography. International Relations. French Tradition. English Tradition.

\section{INTRODUÇÃO}

Grande parte da literatura apresenta o surgimento científico das Relações Internacionais no início do século XX, mais precisa- 
mente em 1917, quando se deu a inauguração de um departamento próprio à disciplina na universidade escocesa de Aberystwyth. Segundo as indicações de NOGUEIRA e MESSARI (2007), os acadêmicos reunidos na referida instituição pautaram seus trabalhos na compreensão ampla da Primeira Guerra Mundial, com a finalidade de buscar caminhos normativos para evitar outros acontecimentos com proporções semelhantes.

Mediante a inevitabilidade do segundo conflito global e o bipolarismo formado após seu encerramento, novas reestruturações foram empreendidas na ciência que nascia. $\mathrm{O}$ novo campo acadêmico foi popularizado e beneficiado pelo lançamento de novas tecnologias que permitiram o contato mais direto entre os pensadores, elaboração de novos recursos, ferramentas e métodos de pesquisa para as Relações Internacionais.

Entre os anos 1980 e 1990, as reestruturações na política internacional lançaram novos desafios para se pensar o mundo. Muitos dos conceitos, modelos e teorias perderam consistência na sustentação da nova realidade da época. Enquanto as grandes tradições teóricas foram colocadas em xeque na tentativa de fornecer justificativas para o cenário complexo que se criava, novas propostas ganharam espaço perante a conjuntura das crises paradigmáticas.

Dessas considerações, percebe-se a visibilidade, ampliação e renovações contínuas lançadas às Relações Internacionais ao longo do último século. De acordo com LAKE (2011), isso parte das próprias condições internacionais, as quais se apresentam aos estudiosos como o sistema social mais complexo de ser entendido e que, por consequência, carece de uma formulação científica única e capaz de 
dar conta da sua totalidade. Nesse sentido é que a pluralidade e a interdisciplinaridade, traços marcantes da ciência em questão, registram iniciativas acadêmicas frutíferas. Para cada um dos pensadores que se debruçam à área, sejam eles historiadores, cientistas políticos, juristas, economistas, sociólogos ou profissionais de outras formações, cada aspecto pode ser tratado sob diferentes abordagens.

E é justamente na trajetória seguida pela História que reside o foco deste trabalho. Seus adeptos, insatisfeitos com os padrões vinculados à Ciência Política para a justificação do mundo, buscam fornecer compreensões mais amplas, que ponderem a política internacional como parte de um processo histórico e que necessita, portanto, ser contextualizado e interpretado sob tal consideração.

Todavia, por mais interdisciplinar que sejam, as Relações Internacionais nem sempre propiciaram um diálogo profícuo entre historiadores e teóricos internacionalistas. Como afirma RAPOPORT (1992), os primeiros são criticados pelo grande foco nos acontecimentos passados em detrimento da análise contemporânea ou futura, enquanto os teoricistas recebem condenações devido às tentativas de sintetizar a complexidade contemporânea em modelos ou conceitos de tendências generalizantes. Longe de tomar ambos os grupos como rivais ou irreconciliáveis, MOURA (1989) interpreta positivamente o diálogo em questão ao reconhecer que, enquanto é crescente a incorporação dos modelos, teorias e conceitos nos trabalhos dos historiadores, ao mesmo tempo é possível identificar iniciativas dos teóricos em invocar a historicidade como elemento para a compreensão do processo de conhecimento. $\mathrm{O}$ que se percebe, assim, é a contribuição mútua de recursos entre tais pesquisadores. 
InterAção | 87

Canonizado enquanto fundador da tendência de invocar a história nas Relações Internacionais, um grupo de franceses foi responsável por inaugurar uma tradição própria. Introduzida por Pierre Renouvin e ampliada por expoentes como DUROSELLE (2000), a tradição francesa teve sua originalidade ao propor explicações dos conceitos recorrentes da área com uma forte sustentação empírica. Não obstante tal excentricidade, historiadores da Grã-Bretanha também produziram importantes obras para a compreensão das Relações Internacionais. Voltados à interpretação do mundo nos termos de uma "sociedade internacional", os ingleses demonstraram a relevância da ordem, bem como das dimensões culturais, éticas e valorativas desse suposto arranjo social.

Isto posto, o presente artigo tem como objetivo entender as contribuições conferidas pelas apreciações historiográficas às Relações Internacionais a partir da análise das duas tradições clássicas da área: a francesa e a inglesa. Para isso, será mapeado inicialmente o campo de estudos da Historiografia em concomitância ao resgate das primeiras obras historicistas voltadas ao estudo dos acontecimentos internacionais. $\mathrm{Na}$ seção seguinte, os traços marcantes da corrente francesa serão elucidados, especialmente através da consideração da obra prima de DUROSELLE (2000) como marco. Posteriormente, o foco se voltará às inovações historiográficas lançadas pela corrente britânica, tomando como referência BULL (2002), seu representante por excelência. Após a síntese de ambas as tradições, o artigo identificará o alcance logrado pelos nódulos centrais de cada abordagem estudada, sem deixar de reconhecer os pontos falhos atribuídos a eles contemporaneamente. A proposta dessas argumentações consistirá 
88 | InterAção

em, justamente, demonstrar os efeitos que as mudanças na realidade internacional geram na produção de pensamentos em Relações Internacionais. Por fim, a partir de tais considerações, alcançar-se-á a resposta para o problema central deste artigo ao reconhecer a contribuição historiográfica às Relações Internacionais como novos meios de estudar a disciplina a partir de perspectivas mais amplificadas contextual e cognitivamente.

\section{0 campo e as primeiras obras}

As explicações históricas para a evolução das ciências é um dos aspectos mais notáveis nas pesquisas contemporâneas. Através desses esforços acadêmicos, procura-se compreender como se criaram as teorias, os contextos do seu nascimento, recursos disponíveis no período, interesses permeados, alcance das abordagens e o envolvimento destas com os demais pensamentos da época. Foi em meio a tais animações que surgiu os estudos da Historiografia das Relações Internacionais.

Resgatando as afirmações de DUNNE (1998), a disciplina historiográfica em Relações Internacionais busca entender como os acontecimentos e movimentos sociais impactam nas ideias e produções acadêmicas deste campo. A atenção é voltada às diferentes abordagens lançadas por grupos de intelectuais para explicar ou interpretar a vida internacional. Nesse sentido é que o autor alarde sobre a importância de considerar os fatores do contexto entre os debates:

A more sophisticated approach [...] would be attentive to the context within which the internal debates were carried forward, retracing the 
InterAção | 89

footsteps of academics who self-consciously and institutionally understood themselves as carrying on a distinctive conversation about International Relations (DUNNE, 1998, p.1)

Pode-se constatar já no século XIX a emersão de literaturas historicistas preocupadas com os movimentos internacionais. Embora não fossem pioneiras, uma vez que se confere comumente a Tucídides (século $\mathrm{V}$ a.C) a iniciativa consagrada de obras acerca das relações entre os povos, somente no período novecentista é que as produções voltadas ao tema assumiram um teor científico.

Dois importantes fatores da época foram influentes nesse sentido, um concernente à política internacional e outro ao desenvolvimento científico. Em primeiro lugar, é mister lembrar a formação dos Estados nacionais e a construção de um sistema baseado nas relações entre essas unidades. Mediante a organização sob o formato estatal, as nações passaram a interagir de modo estratégico para a conquista dos seus interesses, em meio a regras e parâmetros que condicionariam as relações entre si. Por outro lado, no campo intelectual, o período marcou-se pela expressão da chamada "história científica", movimento dominante de oposição à geração romântica. Segundo as explicações de Gerson Moura,

Diferentemente da perspectiva romântica que constituía a história a partir de momentos e de personagens exemplares e se expressava como narrativa literária, a "história científica" apresentava-se como uma corrente contínua de causas e efeitos tangíveis, expressos em linguagem objetiva e impessoal e totalmente despreocupada com valores (MOURA, 1989, p. 68). 
90 | InterAção

Dessas condições, partiram as obras que, por meio de visões realistas, ativeram-se às relações internacionais a partir do epicentro estatal. A preocupação residia em fornecer justificativas à figura do Estado e as posturas que seus representantes tomavam frente aos demais governos. Por transmitir visões intimamente ligadas às estratégias oficiais, essa corrente historiográfica, também conhecida como "história diplomática", teve pouca capacidade crítica o que a fez ser rechaçada por pensadores futuros.

\section{A ruptura historiográfica: 0 nascimento da tradição francesa}

Coube ao professor Pierre Renouvin, célebre historiador francês do século XX, o trabalho de fundar um novo campo mediante o rompimento com a história diplomática. Em seus discursos, o pensador se opunha à perspectiva limitada imposta pelas chancelarias e, mediante ao reconhecimento das falhas metodológicas dessa tradição, convenceu-se sobre a possibilidade de alargar as interpretações acadêmicas:

As forças morais e materiais que agitavam o mundo do seu tempo, como os movimentos nacionais e as forças econômicas, deveriam ser sempre consideradas se o objetivo fosse construir conhecimento mais abrangente e dinâmico da vida internacional. As fontes da pesquisa, portanto, necessitavam ser ampliadas (SARAIVA, 2008, p. 13).

De acordo com SARAIVA (2008), o pioneirismo de Pierre Renouvin, além de consagrar uma tradição francesa na interpretação histórica, também fundou o campo de estudos conhecido como "História das Relações Internacionais". Para Saraiva, o rompimento 
InterAção | 91

com a corrente diplomática possibilitou a inauguração de uma nova disciplina com um objeto próprio, responsável por construir leituras historicistas das relações entre as nações segundo os problemas da vida internacional.

Com a consagrada Histoire des relations internationales, lançada em 1953, Pierre Renouvin edificou um marco ao nortear gerações de estudiosos que desenvolveram suas pesquisas inspirados nas ideias contidas nesta obra. Tal tendência caracterizou uma linhagem de pensamento conhecida, propriamente, como "tradição francesa das Relações Internacionais".

De maneira geral, dois importantes aspectos são notados no trabalho renouviniano. Primeiramente, evidencia-se o caráter permanente dos conflitos interestatais, sobretudo devido à busca incessante das nações por espaço e poder no ambiente internacional. Em segundo lugar, ao ampliar o espectro de análise, a obra enfatizou as relações internacionais para além da Europa, entendidas como resultados do progresso material e promotoras do intercâmbio de ideias, do colonialismo e dos maiores fluxos migratórios. Nascia, desse modo, o conceito de "forças profundas", esmiuçada posteriormente por DUROSELLE (2000), que compreende o conjunto das causalidades sob as quais atuavam os homens no cálculo das suas estratégias (SARAIVA, 2008).

\section{Uma teoria baseada na história: a excentricidade de Duroselle}

DUROSELLE (2000) revelou-se como o herdeiro mais evidente da tradição de Renouvin. Através das palestras e cursos proferidos na Suíça e nos Estados Unidos, Duroselle expandiu os horizontes 
92 I InterAção

da disciplina e conferiu renovação à geração francesa, especialmente com o lançamento da sua obra prima Todo Império Perecerá nos anos 1980.

Já no início do livro, o autor apresenta o objetivo central de construir uma teoria própria, “[...] cuja característica é ser baseada na história, fundada sobre a coletânea de acontecimentos concretos - logo empirica -, sobre suas sucessões - logo evolutiva - e sobre as analogias e as regularidades - logo metódica" (DUROSELLE, 2000, p. 40).

Com o primeiro elemento da teoria, DUROSELLE (2000) se empenhou em refutar as debilidades de interpretar de modo "artificial" a realidade, característica inerente aos conceitos. Ou seja, a incapacidade dos modelos teóricos em abarcar a complexidade da vida levaria a construção de certas falhas como: explicação de um grande número de acontecimentos por meio de um pequeno número de homens; explicação de um grande número de acontecimentos por uma única causa e, finalmente, explicação de um grande número de acontecimentos por meio de um conceito reificado. Dessa forma, o autor invoca a importância da empiria em oposição ao abstrato, e se dedica à formulação de uma teoria das Relações Internacionais com esse teor.

Em segundo lugar, DUROSELLE (2000, p. 21) é crente sobre a impossibilidade de sua teoria ser baseada exclusivamente na racionalidade dos atores. Nas suas palavras, "Devemos, pois, estudar cientificamente o homem; este, porém, é uma mistura de racional e irracional". Isso o levou a identificar dois importantes aspectos: a finalidade, voltada à abrangência dos propósitos e poderes que um 
InterAção | 93

ator tem para realizar seus objetivos; e a causalidade, conjunto de dimensões que exercem forças confusas, que modificam os episódios e a racionalidade. $\mathrm{O}$ reconhecimento de ambas as dimensões seria imprescindível para reconstruir os acontecimentos e as suas sequências dentro da lógica de alternâncias e contrapesos que identifiquem a evolução humana.

Por fim, o pensador propõe três níveis de análise aos estudos historiográficos como meio de não incorrer à generalização, mas, ainda assim, ser capaz de formular perspectivas "seguras". O primeiro deles estaria relacionado às ações pontuais de um dado momento ou circunstância. $\mathrm{O}$ segundo pertenceria às estruturas sociais, ou melhor, a uma das fases lentas da evolução histórica. O último - e, talvez, de maior realce -, englobaria o conjunto da história humana ou as "regularidades":

O exame empírico feito pelo historiador leva-o a constatar a existência repetitiva de certos tipos de acontecimentos ou de conjuntos de acontecimentos apresentando analogias muito fortes e que são completamente independentes dos níveis técnicos e sociais, dos regimes políticos ou das regiões geográficas" (DUROSELLE, 2000, p. 358).

Assim, ao invocar a observação empírica da história internacional, DUROSELLE (2000) conclui a obra prima com o reconhecimento de que, tanto o nascimento quanto a morte dos impérios são uma das grandes "regularidades" da história, ainda que a queda seja resultada por diferentes fatores. O brilhantismo desta formulação tornou-o um dos poucos a identificar o desmoronamento da União Soviética, fato que viria a ocorrer dentro de alguns anos após 
94 | InterAção

a publicação da sua obra magna.

\section{Um outro olhar sobre as relações internacionais: a tradição britânica}

$\mathrm{Na}$ Grã-Bretanha, a origem de uma tradição historiográfica em Relações Internacionais se deu em meados dos anos 1950, intimamente ligada à London School of Economics and Political Science e ao British Committee on the Theory of International Politics. Em torno desta última instituição, reuniram-se autores consagrados como Herbert Butterfield, Martin Wight, Hedley Bull e Adam Watson, tomados por muitos como os fundadores da tradição insular.

Segundo DUNNE (1998), a primeira geração de estudiosos ingleses, embora não compartilhasse laços acadêmicos, debruçava-se sobre conteúdos particulares de estudo. Quando emergiu o British Committee, o corpo de intelectuais adquiriu maior coesão e consciência de grupo, especialmente ao compartilhar certos conceitos e vocabulários. Durante a década de 1960, a tradição assumiu maior amadurecimento e, em meados dos anos 1980, surgiu a controversa expressão "Escola Inglesa" como referência ao conjunto desses trabalhos. Atualmente, o reconhecimento pauta-se na auto-identificação de um autor com a literatura ou corpo de pesquisa inaugurada pelos clássicos dessa tradição.

É importante ressaltar que a corrente britânica, de modo mais elucidativo que a francesa, não se compõe por um corpo homogêneo. Ao contrário, há diferentes perspectivas e abordagens entre seus autores que permitem constatar certo dissenso acerca dos pressupostos centrais da tradição. Por outro lado, mesmo não consensual, o grupo 
insular guarda a marca identitária de busca pelo significado dos conceitos em detrimento da racionalização desses. Em alguns momentos, seus representantes chegaram a rejeitar até mesmo a possibilidade de as relações internacionais serem estudadas de modo científico a partir de um conjunto de causas e efeitos. Como aponta DUNNE (1998), tais autores conseguiram ir além da tendência hegemônica da disciplina, pautada na perspectiva americana de dicotomia entre o racionalismo e o reflexivismo.

Dentre interpretações formuladas para o mundo, aloca-se a célebre ideia de "sociedade internacional" em detrimento do conceito de "sistema internacional". Resgatando a perspectiva lançada por BULL (2002), Ngaire Woods distingue o sistema como o arranjo entre "[...] two or more states which have sufficient contact between them and sufficient impact on one another's decisions to cause them to behave as parts of a whole." Em contraste, a sociedade internacional se caracterizaria por "[...] a group of states which knowingly share common interests and values and 'conceive themselves to be bound by a common set of rules in their relations with one another and share in the working of common institutions" (WOODS, 1996, p. 10).

Aqui, nota-se que ênfase no conceito de sociedade internacional carrega um forte embasamento moral para informar as ações. Disso parte o aspecto normativo da tradição, ou seja, de importância às normas, leis, princípios e valores que sustentam a ordem mundial. Nesse sentido é que os Estados passam a ostentar um caráter de alinhamento ao sentido moral, que encaminha a uma sociedade em que, tanto o conflito quanto a cooperação são possíveis. Em outros termos, ainda que imperfeitas, as relações interestatais não significariam ne- 
96 | InterAção

cessariamente uma catástrofe geral; haveria a possibilidade de ordem.

A análise dos aspectos normativos revela a existência de um debate bipolar entre os historiadores insulares, distintos por BULL (2002) como pluralistas e solidaristas. Conforme explica Emerson de Souza,

[...] o pluralismo descreve sociedades internacionais "tênues" (thin) onde são poucos os valores compartilhados e onde o foco principal é desenvolver regras de coexistência dentro de um quadro de soberania e não-intervenção; o solidarismo, por sua vez, descreve sociedades internacionais "densas" (thick) onde uma maior gama de valores é compartilhada e as regras não são apenas de coexistência, mas também sobre a busca de ganhos comuns e o gerenciamento de problemas coletivos (SOUZA, 2009, p. 134).

\section{Os desencantos do pluralismo de Hedley Bull}

BULL (2002), além de descendente do pensamento de Wight, é mencionado como um dos principais nomes da historiografia britânica. Apesar de ser naturalmente australiano, Bull é entendido como expoente dessa tradição dado os trabalhos científicos que desenvolveu junto à London School, ao British Committee e à Universidade de Oxford.

Um dos traços pelos quais é tradicionalmente lembrado deve-se ao estudo conjunto de dois conceitos que aparentavam ser mutuamente excludentes: a anarquia e a sociedade. Para explicar a combinação de ambos, a partir das luzes de Wight, BULL (2002) afirma existir três tradições observadas ao longo da história para compreender as relações internacionais: a hobbesiana - ou realista; a kantiana 
InterAção | 97

- ou universalista; e a grociana - ou racionalista.

Para os hobbesianos, a política internacional é palco de lutas e guerras em que cada Estado se coloca contra todos os demais. Tais atores assumem liberdade para perseguir seus objetivos sem quaisquer restrições morais ou legais, uma vez que a vida internacional ultrapassa os limites de qualquer sociedade. As únicas regras ou princípios que poderiam circunscrever as ações estatais seriam as concernentes à prudência ou convivência, mediante o interesse dos Estados em respeitar tais acordos.

Já a tradição kantiana, de maneira evidentemente oposta, concebe as relações internacionais como vínculos sociais e transnacionais entre os seres humanos, contexto no qual a possibilidade de conflito é afastada. Isso porque os homens formariam uma comunidade universal e composta por interesses semelhantes, na qual não haveria possibilidades de soma zero. Assim, ao contrário dos hobbesianos, a concepção universalista admite a existência de imperativos morais que limitam a ação dos Estados e busca esforços para sustentar a substituição do mundo por uma sociedade cosmopolita.

Por fim, os comungantes da tradição grociana colocam-se entre as duas correntes supramencionadas e descrevem a política internacional em termos de uma sociedade de Estados ou de sociedade internacional. Nesse sentido, não há empenhos para as lutas diretas entre os Estados por haver limites impostos pelas regras e instituições em comum. De acordo com a interpretação de DUNNE (1998), os atores - que, vale ressaltar, continuam sendo os Estados - mantem a noção subjetiva acerca dos vínculos entre si e identificam os objetivos em comum e as práticas institucionais necessárias para promovê-los. 
98 | InterAção

Porém, ao contrário das noções universalistas, a tradição grociana não prevê o cosmopolitismo, mas sim a aceitação de certas exigências para que haja a coexistência.

Bull sempre demonstrou maior apoio ao racionalismo grociano. Em $A$ Sociedade Anárquica, chega a mencionar a importância dessa perspectiva nas reflexões que considerem a sociedade de Estados e as mutações sofridas por esta. Segundo o autor, a história revelara três padrões de organização internacional: a Sociedade Internacional Cristã (séculos XV, XVI e XVII), a Sociedade Internacional Europeia (séculos XVIII e XIX) e, por fim, a Sociedade Internacional Mundial (século XX) (BULL, 2002).

A compreensão ampliada dessa evolução levou o autor a notar certos elementos que, embora não ocorressem em conjunto nos períodos anteriores, mostrar-se-iam marcantes no atual estágio da política internacional: "a guerra e a disputa pelo poder entre os estados, o conflito e a solidariedade transnacionais, superando as fronteiras dos estados, e a cooperação e o intercâmbio regulado entre os estados" (BULL, 2002, p. 51).

Nesse momento é que o pensamento do autor sofre uma mudança nítida. A concepção pluralista de considerar a sociedade internacional como modo de promover a ordem com base em laços tênues foi abalada pelas constatações de ocorrências nocivas na vida internacional, mesmo perante a existência de condicionantes morais.

Por isso, como revela DUNNE (1998), Hedley Bull reconheceu que a coexistência internacional não poderia ocorrer somente com o consenso ideológico mínimo entre os envolvidos. Em vez disso, seria possível pensar em termos do solidarismo na sociedade internacio- 
InterAção | 99

nal, ainda que o autor tenha demonstrado pessimismo quanto à capacidade deste ocorrer na prática. Com propriedade, Dunne explica:

Bull identified a growing moral solidarity in the late twentieth century [...]. But the key question is how far this awareness translates into sustained moral and political action. Given his recognition of the limits of 'cosmopolitan moral awareness ' his only mechanism for heightening solidarity was through states acting as guardians over global human rights (DUNNE, 1998, p.155).

\section{Um encontro necessário: e historiografia e as relações internacionais}

Em todos os campos do saber humano, de maneira pouco ou muito dinâmica, o desgaste dos postulados geralmente conduz à revisão do campo científico. Dessa tendência não se esquiva a própria disciplina das Relações Internacionais ao evidenciar insatisfações por parte dos seus catedráticos quanto aos padrões analíticos recorrentes. Como demonstra José Flávio Sombra Saraiva, os “[...] problemas, métodos e resultados têm chegado a explicações insatisfatórias, não só para a evolução dos sistemas internacionais ao longo dos últimos séculos, como também para os desafios da interpretação do presente." (SARAIVA, 2008, p. 9).

A busca por redefinições e novas leituras permitiu a incorporação das análises historiográficas às Relações Internacionais desde meados do século XX. Encabeçado por historiadores e certos teoricistas, o empenho procura abordar de modo interdisciplinar o curso da vida internacional sob aspectos contextuais da História. Os esforços, reunidos em torno das grandes tradições de pesquisa, tem pro- 
100 | InterAção

movido perfilhadas renovações ao campo de estudos.

Com notável predicado, MOURA (1989) indica que a historiografia das Relações Internacionais deve ser entendida como um processo intelectual em renovação, decorrente de estímulos "externos" e "internos" à disciplina. Segundo a lição que deixa, é necessário notar, de um lado, os fatores inerentes à política internacional de cada época e os movimentos de ideias e pensamentos gerados no interior dos debates acadêmicos.

Pois bem, internacionalmente, é necessário relembrar acontecimentos como o encerramento das Guerras Mundiais e a conformação de um mundo estruturalmente bipolar. No contexto do ocidente, conformou-se uma ordem centralizada na figura estadunidense em substituição à hegemonia europeia do século XIX. Mesmo coadjuvante no contexto, o Velho Mundo não deixou de expressar certas lideranças, como a francesa e a inglesa, enquanto potências com elevado envolvimento internacional e consagradas pelas tradições científicas influentes. Esse é o grande ambiente dentro do qual se deve compreender e analisar a formação das gerações historiográficas apresentadas anteriormente neste trabalho.

Para os franceses, a preocupação inicial era, evidentemente, buscar outras fontes de pesquisa para marcar o rompimento com a história diplomática. Através da substituição das matérias oficiais do governo, Renouvin e seus companheiros procuraram explicar a evolução internacional a partir de fontes tradicionalmente negligenciadas na literatura da época. Os autores dessa primeira fase, contemporâneos aos abalos e consequências das Guerras Mundiais, vivenciaram a perda da importância relativa da Europa no conjunto das relações in- 
InterAção | 101

ternacionais. Dessa observação, decorreu a busca de explicações para o envolvimento histórico do continente com o restante do mundo.

Todavia, o cenário internacional em meados dos anos 1980 era reconhecidamente diferente do encontrado nas décadas anteriores; as explicações de Renouvin pareciam desconexas para o momento em questão. Convicto da possibilidade de conduzir uma releitura da matriz historiográfica, pode-se dizer que DUROSELLE (2000) trouxe renovação à disciplina francesa, ao formular o Todo Império Perecerá como evidência da maturidade e capacidade de renovação do seu gênero historiográfico.

DUROSELLE (2000) teve um papel fundamental no resgate da tradição francesa, principalmente ao demonstrar a conveniência de grande parte do seu aporte à realidade da época. Em meio às crises paradigmáticas que assolavam as teorias das Relações Internacionais nos anos 1980, o autor soube identificar e conjecturar com propriedade a desarticulação da União Soviética. Além disso, as dissertações acerca do estrangeiro, das fronteiras e dos grupos mostraram importante contribuição para a compreensão dos movimentos de nacionalismo e formação das identidades no Pós-Guerra Fria.

Por outro lado, muito se reflete, atualmente, sobre a visão transmitida pelo autor na referida obra. DUROSELLE (2000) é contestado pela perspectiva nitidamente francesa, além de eurocêntrica, com a qual trata dos temas e da teoria formulada. As próprias noções de fronteiras, identidades, interesses e impérios baseiam-se nas cognições correntes na França que é, vale dizer, um paradigma no modo de organização dos Estados modernos em torno de uma nação. Questões como o atraso, o subdesenvolvimento, a dependência e as assi- 
102 | InterAção

metrias internacionais recebem pouca abertura nas suas elaborações.

Já no ângulo insular, a produção não esteve vinculada aparentemente a tentativas de rompimentos; ao contrário, manteve-se enquanto resultado de tradições de pesquisas cingidas especialmente ao British Committee e à London School. Disso, decorre seu caráter aberto e difuso que, muitas vezes, tornam inviável a tentativa de circunscrever as gerações de autores em torno de aspectos comuns e conferir-lhes, assim, uma grande identidade.

Mesmo assim, como demonstra DUNNE (1998), os britânicos são equivocadamente identificados como corrente teórica do Realismo dada à semelhança das premissas comuns. Ou seja, tanto a tradição historiográfica quanto o paradigma teórico confluem no reconhecimento de que os conflitos interestatais são possíveis e a guerra, ao longo dos séculos, foi a maneira tradicional de encaminhá-los. O ambiente anárquico é considerado aqui como variável influente e dificultosa às iniciativas de cooperação internacional.

Embora convergentes nesses aspectos, DUNNE (1998) ressalta a incompatibilidade de certas concepções como ponto crucial na distinção entre ambos os grupos. Enquanto a tradição britânica busca entender a evolução histórica dos sistemas internacionais que permitem a interpretação desses enquanto sociedades internacionais, o Realismo dedica-se à auto-afirmação como paradigma teórico por excelência das Relações Internacionais. Além das finalidades distintas, o ângulo insular também se contrapõe à Teoria Realista ao reconhecer a possibilidade dos Estados conformarem seus comportamentos e interesses aos princípios normativos. É evidente para essa linhagem a sustentação de uma ordem internacional entre grupos de 
InterAção | 103

Estados que se consideram ligados por certos valores, instituições e objetivos em comum.

Uma perspectiva importante nessa consideração é o pluralismo lançado justamente por BULL (2002), que acredita ser possível ocorrer a ordem mesmo em sociedades internacionais permeadas por laços frouxos. Para o autor, nos contextos pluralistas em que poucos valores são compartilhados, a ordem internacional pode ser lograda mediante as regras básicas de coexistência - como soberania e não intervenção.

Porém, muitos questionamentos são levantados às premissas de Bull no início do presente século. Acontecimentos marcantes do período, como as crises humanitárias, a maior atuação das redes terroristas e a invasão do Iraque liderada pelos Estados Unidos colocam à prova as noções de regras legítimas de coexistência internacional. Em outros termos, o contexto contemporâneo fornece espaço para reavaliar a afirmação de que a sociedade internacional é um fator importante na sustentação da ordem. A grande pergunta que se faz é até que ponto se pode considerar existir uma sociedade com tantas evidências de contradições às supostas normas que a mantém.

Essa inquietação tangenciou também a atenção de BULL (2002) e o fez reconhecer que o conflito com as regras é parte natural da expansão das sociedades internacionais. Todavia, como contrapõe SOUZA (2009), o problema não se pauta na percepção de que as normas são violadas, mas no fato de os participantes da estrutura societária empreender atitudes para desafiá-las. Disso, torna-se questionável as afirmações da sociedade internacional pluralista dada a exacerbação das tensões, contradições e deformidades. Assim, as li- 
teraturas da tradição britânica, atualmente, voltam-se ao estudo de outras questões que ampliam a análise para uma possível sociedade mundial em que os indivíduos passam a ganhar mais atenção.

Com o balanço entre as tradições francesa e inglesa lançado nesta seção, é possível constatar os frutos consolidados da conjugação entre a historiografia e as Relações Internacionais. Ditas em outras palavras, as perspectivas historiográficas na disciplina possibilitaram a compreensão do surgimento, alcances e transformações que as abordagens francesa e inglesa empreenderam durante as últimas décadas.

A observação sob a ótica da historiografia permite averiguar o empenho crescente entre certos historiadores para abarcar conceitos próprios das teorias das Relações Internacionais, ao mesmo tempo em que os teoricistas passaram a prezar pela historicidade em seus trabalhos. A tendência de adotar perspectivas históricas nas análises da disciplina, como visto anteriormente, esteve presente desde os primeiros trabalhos da área e, ao longo do desenvolvimento do campo científico em questão, gerou importantes correntes que abordaram os problemas e acontecimentos da vida internacional de maneira própria. Não se trata de perspectivas alternativas, uma vez que acompanharam o surgimento e a consolidação da disciplina, mas sim de abordagens reconhecidamente capazes de compreender as dimensões estruturais e conjunturais do momento histórico analisado. Como ilumina sabiamente Gerson Moura

A diversificação de objetos e níveis de análise no campo [...] aponta para a conjugação frutífera de dimensões estruturais e conjunturais, de condicionantes externos e internos e de esforços teóricos e 
empíricos, destinados a oferecer explicações cada vez mais compreensivas do convívio internacional (MOURA, 1989, p. 80).

\section{CONCLUSÃO}

Por todas as apresentações e considerações lançadas no decorrer deste trabalho, parece sustentável pensar a importância da historiografia nas Relações Internacionais como possibilidade única de entender a política internacional e sua relação com os movimentos intelectuais. Dessa forma é que se compreende não apenas a aceitação de certas tradições de pensamento, mas também as refutações que são destinadas a elas de acordo com as dinâmicas de cada contexto temporal. Tais perspectivas, compostas por grupos minoritários de estudiosos, entendem a necessidade de incorporação dos fatores históricos e percebem a relevância que a evolução e os acontecimentos passados exercem sobre os conhecimentos produzidos. É nesse sentido que os trabalhos historiográficos oferecem um aporte rico à compreensão dos acontecimentos, sua relação com as produções acadêmicas e os alcances destas. Trata-se de uma ferramenta profícua de criticidade e entendimento das dimensões cognitivas que ampliam os horizontes de análises das Relações Internacionais.

\section{REFERÊNCIAS}

BULL, Hedley. A Sociedade Anárquica. Brasília: Editora Universidade de Brasília, 2002. 
106 | InterAção

DUNNE, Tim. Inventing international society: a history of the English school. London: Macmillan Press, 1989.

DUROSELLE, Jean-Baptiste. Todo império perecerá: Teoria das Relações Internacionais. Brasília: Editora Universidade de Brasília, 2000.

LAKE, David A. Why “isms” Are Evil: Theory, Epistemology, and Academic Sects as Impediments to Understanding and Progress.

International Studies Quarterly, v. 55, p. 465-480. 2011.

MESSARI, Nizar.; NOGUEIRA, João P. Teoria das Relações

Internacionais: correntes e debates. Rio de Janeiro: Elsevier, 2005.

MOURA, Gerson. Historiografia e Relações Internacionais. Contexto Internacional, n. 10, jul-dez. 1989, p. 67-86

RAPOPORT, Mario. Una Teoría sin Historia? El estudio de las relaciones internacionales en cuestión. Ciclos, v.2, n. 3, jul-dez. 1992, p. $147-159$.

SARAIVA, José F. S (Org.). História das relações internacionais contemporâneas: da sociedade internacional do século XX à era da globalização. São Paulo: Saraiva, 2008.

SOUZA, Emerson M. Ordem e Justiça na Sociedade Internacional pós-11 de Setembro. Revista Brasileira de Política Internacional, v.52, n.1, p. 133-148. 2009.

WOODS, Ngaire. Explaning international relations since 1945.

Oxford: Oxford University Press, 1996. 